\title{
Increased peak flow variability in children with asymptomatic hyperresponsiveness
}

\author{
P.G. Gibson, S. Mattoli, M.R. Sears, J. Dolovich, F.E. Hargreave
}

Increased peak flow variability in children with asymptomatic hyperresponsiveness. P.G. Gibson, S. Mattoli, M.R. Sears, J. Dolovich, F.E. Hargreave. (OERS Journals Ltd 1995. ABSTRACT: The relevance of increased methacholine airway responsiveness detected in children with no current or past symptoms of asthma is not known. We wished to determine whether the presence of airway hyperresponsiveness in asymptomatic children is also associated with abnormal variability of peak expiratory flow (PEF).

In 12 asymptomatic children with methacholine hyperresponsiveness, we examined the diurnal variation of peak expiratory flow (PEF) and response to inhaled bronchodilator. Twelve asthmatic children with a comparable range of methacholine hyperresponsiveness, and 12 normal children without methacholine responsiveness, were used as positive and negative controls. The children were aged 11 (range 9-14) yrs.

The mean diurnal variation of PEF in those children with asymptomatic hyperresponsiveness was increased at $9.3 \%$, to a degree comparable to the symptomatic asthmatic children $(\mathbf{1 0 . 7 \%})$, and greater than the normal children $(5.7 \%)$. Methacholine stimulated airway constriction was associated with symptoms in subjects from each group, indicating that the children were capable of perceiving airway constriction.

We conclude that asymptomatic children with methacholine airway hyperresponsiveness have other evidence of mild variable airflow obstruction with increased diurnal PEF variability, and can perceive airflow limitation. The lack of symptoms in the children with airway hyperresponsiveness could be due to an insufficient stimulus to cause symptomatic obstruction, or the absence of esinophilic airway inflammation, which may be a requirement for the development of symptomatic airway hyperresponsiveness.

Eur Respir J., 1995, 8, 1731-1735.
Depts of Medicine and Paediatrics, St Joseph's Hospital and McMaster University, Hamilton, Ontario, Canada.

\section{Correspondence: P.G. Gibson}

Airway Research Centre

Respiratory Medicine Unit

John Hunter Hospital

Locked Bag 1

Hunter Region Mail Centre

NSW 2310

Australia

\section{Keywords: Asthma}

children

methacholine airway responsiveness peak flow variability

Received: December 71994

Accepted after revision June 251995

P.G.G. was a recipient of the Boehringer Research Fellowship. Supported by a grant from the Physicians Services Incorporated.
Recent epidemiological studies have demonstrated that from $8-33 \%$ of children show an increase in airway responsiveness in the absence of any history of dyspnoea, chest tightness, wheezing or recurrent dry cough $[1,2]$. The reasons for this disparity are unclear, but include the possibilities that children with asymptomatic hyperresponsiveness do not experience day-to-day variable airflow obstruction, such as peak flow variability, or that their perception of airflow obstruction differs from symptomatic children. The aims of this study were to determine whether the lack of symptoms in children with asymptomatic hyperresponsiveness was due to failure to recognize airflow obstruction, and to establish whether asymptomatic airway hyperresponsiveness was associated with increased peak expiratory flow (PEF) variability.

\section{Methods}

Three groups, each of 12 children (29 females and 7 males in total), were recruited from children with asthma or rhinitis attending the Firestone Regional Chest and Allergy Clinic, (Hamilton, Ontario, Canada), children of patients and staff of the clinic, and girls who had participated in a previous environmental study (table 1). The children had a mean (SD) age of 11 (2) yrs (range 9-14 years). One group denied any past symptoms of asthma (including a recurrent cough) but had increased methacholine airway responsiveness (asymptomatic AHR) as measured by a lowered PC20 (the concentration provoking a $20 \%$ decrease in forced expiratory volume in one second $\left.<16 \mathrm{mg} \cdot \mathrm{mL}^{-1}\right)$. A second group had symptoms of asthma and methacholine airway hyperresponsiveness (symptomatic AHR) of a similar severity to the asymptomatic group. They required only intermittent inhaled bronchodilator to control their symptoms. The third group denied past symptoms of asthma and had normal methacholine responsiveness of PC20 $>16 \mathrm{mg} \cdot \mathrm{mL}^{-1}$ (Normal). None of the children had symptoms of upper airway infection or exposure to seasonal allergens, to which they were sensitized in the month preceding the study, other respiratory diseases, or forced expiratory volume in one 
Table 1. - Subject characteristics

\begin{tabular}{|c|c|c|c|c|c|c|c|c|c|c|c|c|c|c|c|}
\hline \multirow[b]{2}{*}{$\begin{array}{l}\text { Sub } \\
\text { No. }\end{array}$} & \multicolumn{5}{|c|}{ Normal } & \multicolumn{5}{|c|}{ Asymptomatic AHR } & \multicolumn{5}{|c|}{ Symptomatic AHR } \\
\hline & $\begin{array}{l}\text { Age } \\
\text { yrs }\end{array}$ & Atopy $^{+}$ & $\begin{array}{l}\text { FEV } 1 \\
\% \text { pred }\end{array}$ & $\begin{array}{c}\mathrm{FEV}_{1} / \mathrm{VC} \\
\%\end{array}$ & $\begin{array}{c}\mathrm{PC} 20 \\
\mathrm{mg} \cdot \mathrm{mL}^{-1}\end{array}$ & $\begin{array}{l}\text { Age } \\
\text { yr }\end{array}$ & Atopy ${ }^{+}$ & $\begin{array}{l}\text { FEV1 } \\
\% \text { pred }\end{array}$ & $\begin{array}{c}\mathrm{FEV}_{1} / \mathrm{VC} \\
\%\end{array}$ & $\begin{array}{c}\mathrm{PC} 20 \\
\mathrm{mg} \cdot \mathrm{mL}^{-1}\end{array}$ & $\begin{array}{l}\text { Age } \\
\text { yrs }\end{array}$ & Atopy ${ }^{+}$ & $\begin{array}{l}\text { FEV } 1 \\
\% \text { pred }\end{array}$ & $\begin{array}{c}\mathrm{FEV}_{1} / \mathrm{VC} \\
\%\end{array}$ & $\begin{array}{c}\mathrm{PC} 20 \\
\mathrm{mg} \cdot \mathrm{mL}^{-1}\end{array}$ \\
\hline 1 & 9 & 1 & 98 & 93 & 20.4 & 9 & 9 & 93 & 90 & 1.0 & 9 & 12 & 104 & 88 & 0.6 \\
\hline 2 & 10 & 0 & 96 & 89 & 23.4 & 12 & 8 & 106 & 92 & 2.6 & 12 & 11 & 94 & 81 & 1.2 \\
\hline 3 & 10 & 1 & 102 & 78 & 25.0 & 14 & 1 & 95 & 88 & 3.4 & 11 & 1 & 103 & 86 & 1.4 \\
\hline 4 & 12 & 5 & 90 & 90 & 26.6 & 10 & 4 & 92 & 77 & 3.5 & 10 & 8 & 95 & 80 & 2.6 \\
\hline 5 & 10 & 0 & 119 & 92 & 28.4 & 10 & 0 & 94 & 82 & 3.8 & 14 & 11 & 85 & 87 & 2.7 \\
\hline 6 & 11 & 0 & 122 & 92 & 28.7 & 9 & 2 & 103 & 94 & 4.4 & 9 & 0 & 88 & 83 & 3.3 \\
\hline 7 & 11 & 4 & 82 & 92 & 43.5 & 10 & 10 & 105 & 97 & 5.5 & 13 & 2 & 83 & 93 & 3.6 \\
\hline 8 & 14 & 2 & 101 & 90 & $>64$ & 12 & 3 & 78 & 86 & 5.9 & 11 & 12 & 119 & 89 & 4.5 \\
\hline 9 & 11 & 2 & 95 & 95 & $>64$ & 11 & 12 & 93 & 94 & 6.3 & 12 & 3 & 89 & 87 & 5.0 \\
\hline 10 & 14 & 0 & 97 & 86 & $>64$ & 10 & 2 & 107 & 96 & 7.0 & 11 & 0 & 93 & 80 & 6.7 \\
\hline 11 & 9 & 0 & 90 & 91 & $>64$ & 12 & 1 & 79 & 85 & 7.3 & 12 & 0 & 97 & 93 & 7.9 \\
\hline 12 & 12 & 0 & 95 & 92 & $>64$ & 11 & 0 & 88 & 90 & 13.8 & 12 & 0 & 103 & 84 & 8.0 \\
\hline Mean & 11 & & 99 & 90 & 38.9 & 11 & & 94 & 89 & 4.5 & 11 & & 96 & 86 & 3.1 \\
\hline SD & 2 & & 11 & 4 & 1.6 & 2 & & 10 & 6 & 1.9 & 2 & & 10 & 5 & 2.2 \\
\hline
\end{tabular}

Sub: subject; +: number of positive skin-prick tests; AHR: airway hyperresponsive; FEV1: forced expiratory volume in one second; FEV1/VC: FEV1 as fraction of vital capacity; PC20: provocative concentration of methacholine causing a 20\% fall in FEV1; $\%$ pred: percentage of predicted value.

second as a fraction of capacity (FEV1/VC) $<75 \%$. The children and their parents gave written informed consent. The study was approved by the Research Committee of St Joseph's Hospital, Ontario, Canada.

The children came to the laboratory on three occasions at the same time of day and rested for $15 \mathrm{~min}$. Bronchodilators had been withheld for at least $8 \mathrm{~h}$. At Visit 1, a detailed questionnaire was administered by a physician, to document any history of chest symptoms (including dry cough) and rhinitis, and was that used in previous epidemiological studies in children [2]. Skin tests were performed by the modified skin-prick technique using 12 common allergen extracts. Atopy was defined by at least one $15 \mathrm{~min}$ wheal reaction $>3 \mathrm{~mm}$ diameter. A methcholine inhalation test was performed by the tidal breathing method with methacholine administered in concentrations up to $64 \mathrm{mg} \cdot \mathrm{mL}^{-1}$. During this challenge, the occurrence of chest symptoms at different levels of airflow obstruction was recorded by direct questioning. FEV1 and VC were measured using a Collins $9 \mathrm{~L}$ water spirometer, and results compared with predicted values for Canadian children [3].

For the next 3 days, the subjects measured their peak expiratory flow (PEF) (the best of three attempts) at home on waking, and in the afternoon between 4.00 and 6.00 p.m. [4], using a mini-Wright peak flow meter. The afternoon measurements were repeated after inhalation of salbutamol, $200 \mu \mathrm{g}$ by metered-dose inhaler using a valved holding chamber (Aerochamber, Trudell Medical, Ontario, Canada). Subjects were reviewed on the fifth day (Visit 2) to ensure that measurements and recordings were made correctly. The subjects continued PEF recordings for a further 8 days; only the PEF values from the last 8 days were used for analysis. The variability of PEF over the final 8 days was calculated as the mean difference between the highest PEF value recorded after salbutamol and the lowest PEF value recorded at either of the two time-points each day, expressed as a percentage of the post-salbutamol value [4]. Subjects kept a diary of chest symptoms and any treatment taken over the entire period of PEF recording. At the end of this period (Visit 3), the methacholine inhalation test was repeated to determine whether the level of airway responsiveness had changed or remained constant.

Airway responsiveness was expressed as the PC20 in noncumulative units, and this was obtained using the least squares linear regression analysis of the last two points on the log concentration-response curve. The reproducibility of the PC20 was assessed by calculating the reliability coefficient. This represents the ratio of the variance between subjects to the total variance and was calculated using a one-way analysis of variance (ANOVA) [5]. Higher values indicate higher reliability.

Data were compared across the groups using ANOVA and Newman-Keuls' multiple range test. Differences in the results obtained in the asthmatic and asymptomatic children were also analysed by the unpaired Student's ttest. The Chi-squared test was used to analyse frequency data. Significance was accepted at the $95 \%$ level.

\section{Results}

Diurnal variability of PEF in children with asymptomatic AHR was similar to that in asthmatic children (fig. 1 ). The mean diurnal variability of PEF, including the effects of bronchodilator, was $9.3 \pm 2.8 \%$ in children with asymptomatic AHR, $10.4 \pm 3.0 \%$ in symptomatic AHR asthmatics and $5.7 \pm 1.8 \%$ in normal children $(\mathrm{p}<0.05)$. The degree of diurnal variation in PEF correlated with the degree of methacholine airway responsiveness in those subjects in whom a PC20 was obtained $(r=-0.56 ; \mathrm{p}<0.01)$ 


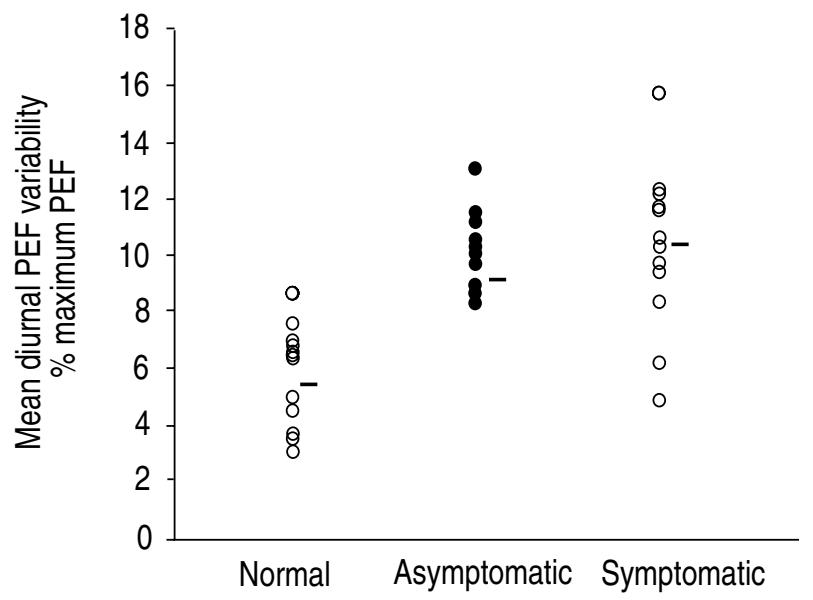

Fig. 1. - Mean diurnal variability of PEF, expressed as percentage of highest daily value record, in the individual subjects of the three groups of children. Bar line represents mean value for each group. Children with asymptomatic methacholine AHR $(\mathbf{O})$ had peak flow variability comparable to the symptomatic, asthmatic children and greater than normal children $(\mathrm{p}<0.05)$. PEF: peak expiratory flow; AHR: airway hyperresponsiveness.

(fig. 2). The proportion of children with diurnal variability of PEF beyond the reported upper 95\% confidence limit for normals [4] was $83 \%$ in the asymptomatic AHR group. This was similar to the proportion in the symptomatic AHR group (83\%) $(\mathrm{p}=1.0)$, and significantly higher than in the normal group $(16 \%)(\mathrm{p}=0.004)$.

The baseline FEV1 during the study varied by less than $10 \%$ in each child. Airway responsiveness to methacholine, expressed as PC20, on Visits 1 and 3 (which were separated by 12 days) was highly reproducible in asthmatic, asymptomatic and normal children with reliability coefficients of $0.89,0.96$ and 0.85 , respectively, indicating that the individual degrees of responsiveness were stable during the study.

During the 14 day observation period, no symptoms were recorded on the diary cards of the normal and asymptomatic children, whereas respiratory symptoms were reported by 7 of the 12 asthmatic children. Respiratory

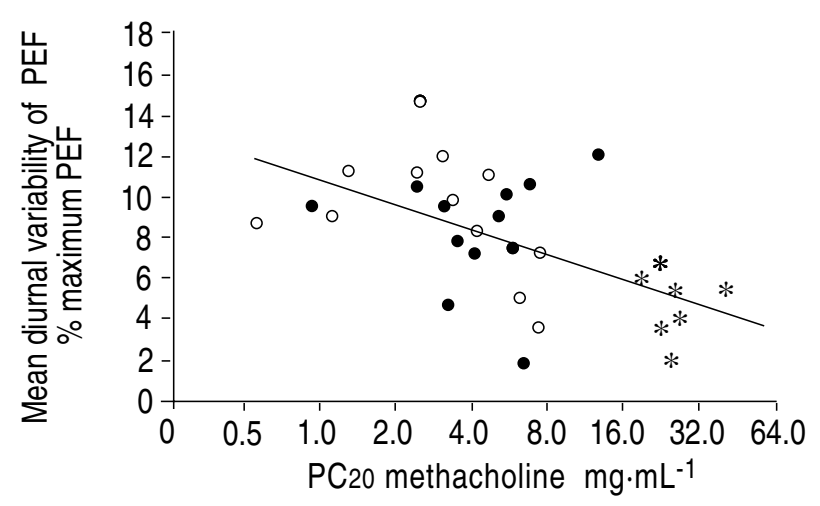

Fig. 2. - Relationship between methacholine airway responsiveness expressed as $\mathrm{PC} 20$, and diurnal variability in peak expiratory flow rates (PEF) as percentage of highest PEF in asymptomatic (O) symptomatic $(\mathrm{O})$ and normal children in whom a $\mathrm{PC}_{20}$ was obtained $(*)$. $(\mathrm{r}=-0.56 ; \mathrm{p}<0.01)$. $\mathrm{PC} 20$ : concentration of methacholine provoking a $20 \%$ decrease in forced expiratory volume in one second. symptoms developed during the methacholine inhalation tests in 12 of the 12 asthmatic, 12 of the 12 asymptomatic and 11 of the 12 normal children. The symptoms reported by the asthmatic children were invariably recognized as having been felt previously, whereas the symptoms reported by the normal children had not been experienced previously. Of the asymptomatic children, 10 reported the symptoms as completely new, and two reported prior experience of the symptoms (chest tightness).

The prevalence of atopy was similar in the three groups: 10 of the 12 asymptomatic, 8 of the 12 asthmatic, and 6 of the 12 normal children ( $p>0.10)$. Rhinitis was more frequent in the children with airway hyperresponsiveness: (asymptomatic 8 of the 12, asthmatic 8 of the 12 versus normal children 2 of the 12$)\left(\mathrm{Chi}^{2}=4.29 ; \mathrm{p}<.05\right)$.

\section{Discussion}

This study demonstrates that children with airway hyperresponsiveness to methacholine, but without current or past symptoms suggesting asthma, show a degree of variability of airflow limitation significantly greater than normal children, and similar to that found in known asthmatics. In these children, diurnal PEF variability correlated directly with the degree of methacholine airway hyperresponsiveness. The results indicate that increased PEF variability alone is insufficient to generate symptoms of asthma.

Similar results have been found in adults with allergic rhinitis and no symptoms of asthma. Airway hyperresponsiveness was associated with an increased diurnal variation in PEF $[6,7]$. In the present study, rhinitis was also associated with AHR. It should be noted that we examined diurnal variability of PEF, including the effects of bronchodilator. This would increase the numerical estimate of variability. Importantly, however, the same measurement was made in each group and, despite a similar degree of PEF variability to the symptomatic group, children with asymptomatic methacholine airway hyperresponsiveness recorded no symptoms during the period of observation. There may be several reasons for the lack of respiratory symptoms (cough, wheeze, dyspnoea) in these children with AHR. The possibilities include: poor recognition of variable airflow obstruction; failure to recognize symptoms; and limited inflammatory cell infiltration into the airways.

We examined the ability of children to recognize airway constriction and found this to be similar in all three groups. This agrees with data from PIN et al. [8] who also studied perception of dyspnoea in asymptomatic AHR. In contrast, BRAND et al. [9] found that adults with asymptomatic hyperresponsiveness were less likely to report dyspnoea during a histamine inhalation test. There are several reasons for these different results. Importantly, the degree of induced airway constriction was less in the study of BRAND et al. [9], since the test was stopped when the FEV1 fell by $10 \%$ or a final concentration of $32 \mathrm{mg} \cdot \mathrm{mL}^{-1}$ histamine was given. The definition of a symptom response was also restricted to dyspnoea alone. We have found that the application of a sufficiently strong 
stimulus caused a range of respiratory symptoms in children with AHR, and that this occurred equally in those with and without prior respiratory symptoms. A further difference is subject selection. BRAND et al. [9] studied a population sample, whereas our subjects were selected. This may also limit the ability to generalize the observations.

We also examined the possibility that the children with asymptomatic AHR had not recognized or recalled prior symptoms of airway constriction. Only two of the 12 asymptomatic children indicated that symptoms which occurred during the methacholine test had occurred previously. These two children were, therefore, misclassified by the questionnaire. Overall, the results indicate that children with asymptomatic AHR are able to recognize symptoms caused by airway constriction when this leads to a clinically significant fall in FEV1 $(>20 \%)$. The lack of day-to-day symptoms could occur if these children do not develop sufficient airway constriction in response to natural stimuli, such as exercise and cold air, to which they are exposed. This hypothesis is supported by observations that children with asymptomatic AHR are less likely to develop airway constriction in response to isocapnic hyperventilation of cold dry air [8].

Airway inflammation is an integral part of symptomatic asthma. Airway inflammation does not appear to be present in asymptomatic AHR when assessed by induced sputum [8], or bronchial biopsies [10]. Airway inflammation can occur without AHR and be sufficient to cause symptoms of chronic cough but not wheeze and breathlessness [11]. The results of this study indicate that mild variable airflow obstruction alone may not be sufficient to cause wheeze and breathlessness on a day-today basis either. A combination of airway inflammation and airway hyperresponsiveness may, therefore, be required to lead to symptoms of episodic wheeze and breathlessness. The effects of coexisting airway inflammation may be to change the intensity or quality of the symptoms or to increase the susceptibility to indirect stimuli, such as exercise or inhalation of cold air.

The prognosis for children with asymptomatic AHR is variable. In those instances where symptoms occur but are not recognized or recalled (questionnaire misclassification), it would be expected that symptoms could subsequently be recognized and that these children would develop symptomatic hyperresponsiveness. This has been documented to occur in about $20 \%$ of subjects with AHR defined by methacholine [12], or exercise challenge [13]. The majority however remain asymptomatic, and their AHR either resolves or persists [12-14]. These observations suggest that asymptomatic AHR is a "benign" condition that, in general, is not associated with airway inflammation or the subsequent development of clinical asthma. This raises questions as to the mechanism(s) of asymptomatic AHR in childhood.

Wheezing is a very common symptom in early childhood [15]. It can occur independent of allergy when it is associated with small airway size, frequent viral respiratory tract infections, and other risk factors. Wheeze frequently resolves after early childhood; however, the residual effects of these conditions could explain the persistence of asymptomatic AHR into later childhood. If this is the case, then detailed study of children with asymptomatic AHR could identify factors which protect against the development or persistence of wheezing in later childhood years. One possible factor includes an immune response that suppresses T-cell reactivity and which may be characterized by a specific macrophage phenotype [10, 16], or B-cell response [17].

In conclusion, this study demonstrates that although children with asymptomatic AHR do not have day-to-day symptoms of asthma, they are capable of recognizing symptoms of airway constriction and have increased PEF variability. The development of day-to-day symptoms of asthma requires factors in addition to variable airflow limitation. These factors may include exposure to a sufficiently strong stimulus and the presence of eosinophilic airway mucosal inflammation.

Acknowledgements: The authors thank all the children participating in the study and their parents, Glaxo Canada Ltd (Mississauga, Ontario Canada) for the supply of salbutamol, Trudell Medical (London, Ontario Canada) for the supply of the Aerochambers, and G. Sheather for typing the manuscript.

\section{References}

1. Lee DA, Winslow NR, Speight ANP, Hey EN. Prevalence and spectrum of asthma in childhood. Br Med J 1983; 286: $1256-1258$.

2. Sears MR, Jones DT, Holdaway MD, et al. Prevalence of bronchial reactivity to inhaled methacholine in New Zealand children. Thorax 1986; 41: 283-289.

3. Weng T-R, Levison H. Standards of pulmonary function in children. Am Rev Respir Dis 1969; 99: 879894.

4. Ryan G, Latimer KM, Dolovich J, Hargreave FE. Bronchial responsiveness to histamine: relationship to diurnal variation of peak flow rate, improvement after bronchodilator, and airway calibre. Thorax 1982; 37: 423-429.

5. Kramer MS, Feinstein AR. Clinical biostatistics LIV. The biostatistics of concordance. Clin Pharmacol Ther 1981; 29: 111-123.

6. Ramsdale EH, Morris MM, Robert RS, Hargreave FE. Asymptomatic bronchial hyperresponsiveness in rhinitis. J Allergy Clin Immunol 1985; 75: 573-577.

7. Townley RG, Ryo UY, Kolotkin BM, Kang B. Bronchial sensitivity to methacholine in current and former asthmatic and allergic rhinitis patients and control subjects. J Allergy Clin Immunol 1975; 56: 429-442.

8. Pin I, Radford S, Kolendowicz R, et al. Airway inflammation in symptomatic and asymptomatic children with methacholine hyperresponsiveness, Eur Respir $J$ 1993; 6: 1249-1256.

9. Brand P, Rijcken B, Schouten JP, Koeter GH, Weiss ST, Postma DS. Perception of airway obstruction in a random population sample. Am Rev Respir Dis 1992; 146: 396401.

10. Power C, Sreenan S, Hurson B, Burke C, Poulter LW. Distribution of immunocompetent cells in the bronchial wall of clinically healthy subjects showing bronchial hyperresponsiveness. Thorax 1993; 48: 1125-1129.

11. Gibson PG, Dolovich J, Denburg J, Ramsdale EH, 
Hargreave FE. Chronic cough: eosinophilic bronchitis without asthma. Lancet 1989; i: 1346-1348.

12. Zhong NS, Chen RC, Yang MO, Wu ZY, Zheng JP, $\mathrm{Li}$ YF. Is asymptomatic bronchial hyperresponsiveness an indication of potential asthma? Chest 1992; 102: 1104-1109.

13. Jones A. Asymptomatic bronchial hyperreactivity and the development of asthma and other respiratory tract illnesses in children. Thorax 1994; 49: 757-761.

14. de Gooijer A, Brand PLP, Gerritsen J, Koeter GH, Postma DS, Knol K. Changes in respiratory symptoms and airway hyperresponsiveness after 27 years in a population-based sample of school children. Eur Respir $J$ 1993; 6: 848-854.

15. Wilson NM. The significance of early wheezing. Clin Exp Allergy 1994; 24: 522-529.

16. Hutter C, Poulter LW. The balance of macrophage subsets may be customized at mucosal surfaces. FEMS Microbiol Immunol 1992; 105: 309-315.

17. Gleeson M, Clancy RL, Cripps AW, Henry RL, Hensley MJ, Wlodarczyk JW. The significance of transient mucosal IgA deficiency on the development of asthma and atopy in children. Adv Exp Med Biol 1995; (in press). 